Archived version from NCDOCKS Institutional Repository http://libres.uncg.edu/ir/asu/

Cherry, T. L., Cotton, S. J., \& Kroll, S. (2013). Heterogeneity, coordination, and the provision of best-shot public goods. Experimental Economics, 2013(4), 497-510. Publisher's version available from

www.springer.com (ISSN: 1386-4157). DOI 10.1007/s10683-012-9349-1

\title{
Heterogeneity, Coordination and the Provision of Best-Shot Public Goods
}

Todd L. Cherry · Stephen J. Cotten · Stephan Kroll

\begin{abstract}
In a best-shot public good, where the provision level is determined by the highest contribution instead of the sum of all contributions, there is potential for waste and underprovision due to coordination failure. These failures are exacerbated when agents are identical because there is no focal point to guide coordination. In most real-world best-shot public-good situations, however, heterogeneity exists in the ability to contribute and the benefits received from the good. With such differences, shared expectations might emerge to improve coordination and increase efficiency. Using laboratory experiments, we find significant behavioral responses to heterogeneity that improve efficiency, but not always from increased coordination.
\end{abstract}

\section{Keywords}

Best-shot public goods, Coordination problem, Endowment heterogeneity, Return heterogeneity, Experiment 


\section{Introduction}

When a public good is provided through a best-shot mechanism (Hirshleifer 1983; Bliss and Nalebuff 1984; Harrison and Hirshleifer 1989), the maximum individual contribution rather than the sum of all contributions determines the level of the good. This supply technology mimics many social problems, such as finding a cure for disease, calling an ambulance for a roadside accident, or providing a tsunami warning system, and is particularly relevant for regional, international, and global public goods (Holzinger 2001; Sandler 2006). Best-shot public goods sit at the intersection of two types of provision problems: free-riding and coordination failure. Free-riding arises because in most constructions each individual is better off if someone else provides the good and coordination failures occur because groups find it difficult to coordinate on one of the multiple equilibria-i.e., identifying which member contributes the optimal amount while all other members avoid duplicating the contribution.

Beginning with Schelling's (1960) seminal work, the literature generally accepts that shared expectations can yield focal points that distinguish one equilibrium from others (e.g., Mehta et al. 1994; Camerer 2003). Such expectations rely on the existence of heterogeneity in one or more dimensions.1 For best-shot public goods, two potential sources of heterogeneity are the ability to contribute (endowment) and the benefits received from the good (marginal private return). For example, the ability to contribute to the development of a cure for malaria varies by differences in resources, while the benefits of a cure vary by location-specific environmental attributes (e.g., malaria is concentrated in warm, wet regions). If one potential contributor has more resources than the others and therefore can achieve greater levels of provision, there may be a shared expectation that this agent will be the contributor. Alternatively, a potential contributor that stands to benefit the most from the public good might be expected to be the contributor for self-interested reasons-she has the most to lose from failed provision of the public good. The literature offers some indication that such heterogeneity can facilitate cooperation in the provision of best-shot public goods. Kroll et al. (2007) introduces endowment heterogeneity in a one-shot best-shot public good game, and though the focus of the study is not coordination, it reports that homogeneous treatments suffer from coordination failure while groups with heterogeneous endowments tend to coordinate on the optimal outcome.

There is an extensive literature that examines coordination problems, including variants of the market-entry game, battle-of-the-sexes game and minimum-effort games, but little attention is directed to exploring coordination in the best-shot public good game. Yet the game offers a useful framework to investigate coordination and efficiency because coordination failures can occur from people contributing too much (multiple agents making duplicate contributions that are wasted) or contributing too little (the largest contributor giving less than the optimal amount). Indeed, a group can commit both missteps simultaneously. This closely resembles the volunteer's dilemma, in which each person of a group faces a binary choice on whether to volunteer to provide a public good for her group (Diekmann 1985). Each subject is better off if the good is provided, but would be best off if someone else provided it. Experimental studies of the volunteer's dilemma generally impose homogeneity in endowments and returns (e.g., 
Bilodeau et al. 2004; Goeree et al. 2005; Hörisch and Kirchkamp 2010), but a working paper by Healy and Pate (2012) introduces heterogeneity in the cost of provision. Their results indicate that cost heterogeneity improves coordination with group members more frequently selecting an equilibrium in which the low-cost member decides to volunteer while the others do not.

Herein we examine the influence of within-group heterogeneity on the coordination and provision of a best-shot public good. We consider heterogeneous endowments and returns, separately and together, and find interesting differences between the two sources of heterogeneity. We find that heterogeneity in endowments is quite effective, having a large positive effect on coordination and efficiency. Results are mixed regarding heterogeneous returns-efficiency improves, but coordination does not. This divergent outcome arises because while heterogeneity in returns does not facilitate better coordination, it does change the nature of the coordination failures.

\section{Theoretical background}

Consider a group of $n$ players with endowments $\left\{e_{1}, \ldots, e_{n}\right\}, e_{1} \geq e_{2} \geq \cdots \geq e_{n}$ who make contributions of $\{c 1, \ldots, c n\}$ to a best-shot public good. Each player receives a marginal private return $\{r 1, \ldots, r n\}$ for each unit of the public good and the level of the good is equal to the largest individual contribution, $\max (c 1, \ldots, c n)$, so that the publicgood income, $C j$, for group member $j$ is $C j=r j \times \max (c 1, \ldots, c n)$. Total income is therefore $l j=C j+e j-c j$.We restrict our analysis to the most interesting case of $r j>1$ for all $j$.

First, a necessary condition for a Nash Equilbrium (NE) is that one player contributes her entire endowment and all other players contribute nothing. Intuitively, the nature of the best-shot good rules out multiple players contributing as an equilibrium, as any duplicated contributions are wasted leaving at least one player a profitable deviation to contribute nothing. Similarly, because the marginal private return from the public good exceeds one $(r j>1)$, it cannot be a Nash equilibrium (NE) for the single-contributor to contribute less than her full endowment, because there is a profitable deviation to increase contributions to the maximum.

However, this condition is only sufficient for identical endowments. When endowments are heterogeneous, the contribution vector $\{e 1,0, \ldots, 0\}$ is a NE since nobody other than player $j=1$, by construction the player with the highest endowment, can increase their payoff by contributing. Other NE may exist, but are dependent on marginal private returns. For any $1 \leq j \leq n,\{0, \ldots, 0, e j, 0, \ldots, 0\}$ is a NE if no player can increase his or her payoffs by unilaterally contributing their full endowment, which is true if the following holds:

$$
r_{i} e_{j}+e_{i} \geq r_{i} e_{i}, \quad \forall i \neq j
$$


If an agent with an identical or higher endowment contributes everything to the public good, then a person with a lower endowment always does best by not contributing anything. Thus, condition (1) is fulfilled for all $i$ with $e i \leq e j$ and we can transform it into

$$
r_{i} \leq \frac{e_{i}}{e_{i}-e_{j}}, \quad \forall i<j
$$

If $r 1>e 1 /(e 1-e 2)$, it is a dominant strategy for the highest-endowment player to contribute everything, and thus everyone else contributes nothing.

Thus the task of providing a best-shot public good takes the form of an anticoordination game (e.g., chicken game) - the group is best served by an asymmetric strategy, in which someone contributes their full endowment and nobody else contributes at all. With no heterogeneity in endowments or returns, game theory suggests chaos; there is nothing to guide coordination on a pure strategy, and mixed strategies do not facilitate efficient provision. Heterogeneity can potentially help coordination by eliminating Nash equilibria and by creating group members "marked" for contributions; heterogeneous endowments create group members who can clearly maximize group welfare and heterogeneous returns create group members who have the most to lose from failed provision. But a new mystery arises when there are both sources of heterogeneity and multiple players are "marked" at the same time. To sort out the relative strength of the sources of heterogeneity, we turn to a laboratory analysis.

\section{Experimental design}

\subsection{Basics}

One hundred ninety-two undergraduate students were recruited from the student body at the University of Tennessee to participate in a computerized best-shot public good game. All subjects were unfamiliar with the best-shot mechanism, and written protocols ensured uniformity in procedures. All sessions were programmed and conducted using the software Z-Tree (Fischbacher 2007) with instructions displayed on-screen to subjects while a monitor read them aloud. Instructions concluded with a series of questions and answers and two practice periods to reinforce subject understanding. At the end of the experiment, subjects were called one at a time to be paid privately and in cash, with real earnings on average of approximately $\$ 20$ for sessions lasting roughly forty-five minutes.

\subsection{Setting}

In each session, 16 subjects were randomly placed in groups of four and groups were reshuffled after each period (a "random stranger" design). Group members were not identified to one another, and communication between subjects was prohibited. A decision period began with subjects receiving an endowment of lab tokens which they simultaneously and anonymously allocated between a public account that provided a return on the highest individual contribution and a private account that provided a return 
of one per token invested. After all subjects made their decisions, they viewed their earnings from the private account, whether they were the largest contributor to the public account, the amount of the largest contribution to the public account, and the amount they earned from the public account. Each session had 20 rounds-each with new groups, endowments and values.

\subsection{Treatments}

The experiment followed a $2 \times 2$ design that varied homogeneity and heterogeneity conditions over endowments and marginal private returns. Therefore, we have the following four treatments: a baseline with homogeneous endowments and homogeneous returns $\left(e^{h o} r^{h o}\right)$, heterogeneous endowments and homogeneous returns (eherho), homogeneous endowments and heterogeneous returns $\left(e^{h o} r^{h o}\right)$, and heterogeneous endowments and heterogeneous returns $\left(e^{h o} r^{h o}\right)$. In homogeneous endowment treatments, all members of the group received the same endowment in each period drawn randomly from the values of $10,20,30$, or 40 tokens and were aware that each member of the group had the same endowment. In heterogeneous endowment treatments, each member had a different endowment randomly assigned from $10,20,30$, or 40 with each value held by a member of the group. The same is true for returns with values of $1.25,2,3$, and 3.75 . We conducted 12 sessions, three sessions for each treatment, yielding 960 group and 3840 individual observations.

\subsection{Predictions}

The various combinations of homogeneous and heterogeneous endowments of 10,20 , 30,40 and marginal private returns of 1.25, 2, 3 and 3.75 yield the Nash equilibria shown in Table 1.4 With $\left(e^{h o} r^{h o}\right)$ (baseline), all Nash equilibria yield the same payoffs and there is nothing to guide players toward selecting a particular Nash equilibrium. Thus, in the homogeneous baseline treatment $\left(e^{h o} r^{h o}\right)$, we expect poor coordination and inefficiency from duplicate contributions and undercontribution. Introducing

heterogeneity in returns $\left(e^{h o} r^{h o}\right)$, the Nash equilibria remain unchanged and all still yield identical payoffs. However, the presence of heterogeneity in returns opens the door for coordination, with the likely contributor being the group member with the most to lose if the good is not provided: the person with the highest return. Thus, in $\left(e^{h o} r^{h o}\right)$, we expect improved coordination and greater efficiency relative to the baseline. 
Table 1 Nash equilibria in pure strategies

\begin{tabular}{|c|c|c|}
\hline Endowments & Marginal private returns & Nash equilibria \\
\hline Homogeneous & Homogeneous or Heterogeneous & $\begin{array}{l}\text { One person contributes all; } \\
\text { others contribute nothing }\end{array}$ \\
\hline Heterogeneous $(40,30,20,10)$ & Homogeneous (all 1.25) & $\begin{array}{l}(40,0,0,0), \\
(0,30,0,0), \\
(0,0,20,0), \\
(0,0,0,10)\end{array}$ \\
\hline Heterogeneous $(40,30,20,10)$ & Homogeneous (all 2) & $\begin{array}{l}(40,0,0,0), \\
(0,30,0,0) \\
(0,0,20,0)\end{array}$ \\
\hline Heterogeneous $(40,30,20,10)$ & Homogeneous (all 3 or all 3.75 ) & $\begin{array}{l}(40,0,0,0) \\
(0,30,0,0)\end{array}$ \\
\hline Heterogeneous $(40,30,20,10)$ & $\begin{array}{l}(1.25,2,3,3.75) \text { or } \\
(1.25,2,3.75,3)\end{array}$ & $\begin{array}{l}(40,0,0,0), \\
(0,30,0,0), \\
(0,0,20,0)\end{array}$ \\
\hline Heterogeneous $(40,30,20,10)$ & $\begin{array}{l}(2,3,1.25,3.75) \text { or } \\
(2,3,3.75,1.25) \text { or } \\
(2,1.25,3,3.75) \text { or } \\
(2,1.25,3.75,3)\end{array}$ & $\begin{array}{l}(40,0,0,0) \\
(0,30,0,0) \\
(0,0,20,0)^{*}\end{array}$ \\
\hline Heterogeneous $(40,30,20,10)$ & All other combinations & $\begin{array}{l}(40,0,0,0) \\
(0,30,0,0)\end{array}$ \\
\hline
\end{tabular}

"Indicates a weakly dominated NE

When heterogeneity is only in endowments $\left(e^{h o} r^{h o}\right)$, a clearer story emerges. While multiple Nash equilibria still exist, they are no longer equally efficient. There is a Paretooptimal Nash equilibrium - the person with the highest endowment contributes the entire 40 and the others contribute zero. We therefore expect $\left(e^{h o} r^{h o}\right)$ to provide a relatively strong focal point and facilitate increased coordination and greater efficiency relative to the baseline.

In the case of heterogeneity in both endowments and returns $\left(e^{h o} r^{h o}\right)$, the situation becomes murkier. Heterogeneity exists in two dimensions and presents alternative potential focal points. A priori it is not entirely clear which, if any, focal point will facilitate coordination and these are experimental questions we test. However, the presence of heterogeneity provides the potential for coordination, so we anticipate some improvement in coordination and efficiency as compared to the homogeneous baseline, though we suspect the multiple potential focal points will frustrate coordination relative to the treatments with a single focal point.

\section{Results}

Higher contributions to a best-shot public good are not synonymous with higher efficiency, as in a summation public good, so we analyze contributions and efficiency separately. We first review individual contributions before moving to an examination of coordination and efficiency. 
Table 2 Mean individual contribution as a percentage of endowment by treatment, endowment and return Treatment Endowment

\begin{tabular}{llllllllll} 
& 10 & 20 & 30 & 40 & 1.25 & 2.00 & 3.00 & 3.75 & \\
\hline$e^{h o} r^{h o}$ & $31 \%$ & $29 \%$ & $27 \%$ & $29 \%$ & $19 \%$ & $25 \%$ & $36 \%$ & $36 \%$ & $29 \%$ \\
& $(4.1 \%)$ & $(3.9 \%)$ & $(4.0 \%)$ & $(4.4 \%)$ & $(3.3 \%)$ & $(3.9 \%)$ & $(4.3 \%)$ & $(4.9 \%)$ & $(3.3 \%)$ \\
$e^{h o} r^{h e}$ & $36 \%$ & $34 \%$ & $39 \%$ & $41 \%$ & $17 \%$ & $28 \%$ & $43 \%$ & $62 \%$ & $38 \%$ \\
& $(4.2 \%)$ & $(4.2 \%)$ & $(4.3 \%)$ & $(4.6 \%)$ & $(4.6 \%)$ & $(4.9 \%)$ & $(4.7 \%)$ & $(5.5 \%)$ & $(3.4 \%)$ \\
$e^{h e} r^{h o}$ & $5 \%$ & $7 \%$ & $16 \%$ & $85 \%$ & $25 \%$ & $30 \%$ & $29 \%$ & $29 \%$ & $28 \%$ \\
& $(2.2 \%)$ & $(1.7 \%)$ & $(3.7 \%)$ & $(3.5 \%)$ & $(3.1 \%)$ & $(3.5 \%)$ & $(3.5 \%)$ & $(3.0 \%)$ & $(2.1 \%)$ \\
$e^{h e} r^{h e}$ & $9 \%$ & $17 \%$ & $33 \%$ & $75 \%$ & $28 \%$ & $29 \%$ & $37 \%$ & $41 \%$ & $34 \%$ \\
& $(2.3 \%)$ & $(4.3 \%)$ & $(4.9 \%)$ & $(3.8 \%)$ & $(4.1 \%)$ & $(3.6 \%)$ & $(3.8 \%)$ & $(3.7 \%)$ & $(2.9 \%)$ \\
Pooled & $20 \%$ & $22 \%$ & $29 \%$ & $57 \%$ & $22 \%$ & $28 \%$ & $36 \%$ & $42 \%$ & $32 \%$ \\
& $(1.9 \%)$ & $(2.0 \%)$ & $(2.2 \%)$ & $(2.8 \%)$ & $(1.9 \%)$ & $(2.0 \%)$ & $(2.1 \%)$ & $(2.3 \%)$ & $(1.5 \%)$ \\
\hline
\end{tabular}

The top number in each cell is the average percentage of the endowment invested in each round. The number in parentheses is the robust standard error of the percentage of endowment investment

\subsection{Contributions}

Table 2 summarizes mean relative individual contributions defined as a percentage of endowment by treatment, endowment, and return. At the treatment level, the contribution levels are similar across the four treatments, ranging from $28 \%$ to $38 \%$, rather close to the $25 \%$ contribution rate in any pure-strategy Nash equilibrium in which one person contributes $100 \%$ and the other three $0 \%$. Substantial variation in contributions arises, however, once the data is stratified by endowment and return.

First, consider the mean individual relative contributions by endowment levels reported in columns 1 through 4 of Table 2 . In the two treatments with homogeneous endowments, contribution levels are not statistically different across endowment levels. This is not the case when endowments are heterogeneous. In both treatments with heterogeneous endowments, the subjects with the high endowment contribute substantially more than the other three (combined). 6 Note the subtle difference between the two heterogeneous endowment treatments. When returns are also heterogeneous, the contributions by subjects with an endowment of 40 are not as close to $100 \%$ and the contributions of subjects with other endowments are not as close to 0 . This may indicate that the influence of heterogeneous endowments as a focal point may be diminished by the presence of the additional heterogeneity in returns, a point to which we will return in the next subsection.

Next, turn to the mean individual relative contributions by return levels reported in columns 5 through 8 of Table 2. As expected, we observe a general increase in contributions 

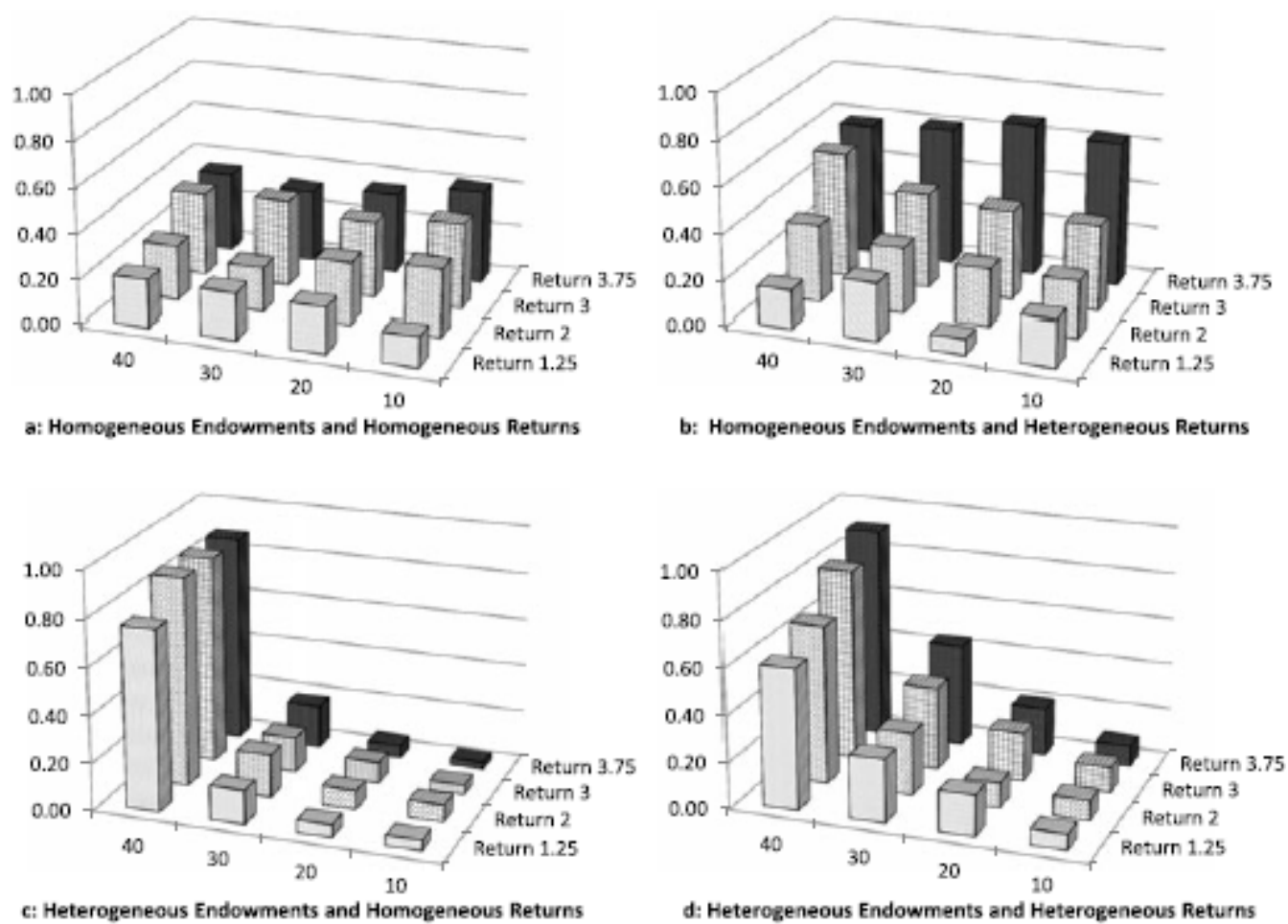

Fig. 1 Mean contribution levels as a percent of endowment by endowment and return for each treatment

as the return from the public good increases, but the positive impact of returns on contributions is substantially greater when returns are heterogeneous within the group. This is particularly true when endowments are homogeneous (ehorhe); in this case, the subjects with the highest return (3.75) contribute nearly twice as much if the returns are heterogeneous than homogeneous (62\% versus $36 \%$ ).

Figure 1 illustrates the distribution of contributions in the four treatments. Figure $1 \mathrm{a}$ shows average relative individual contribution levels when endowments and returns are homogeneous (ehorho); as expected, no obvious pattern emerges since members of a group have no focal point to coordinate on. In Figs. 1b and 1c, however, when either returns or endowments are heterogeneous within a group while the other variable is homogeneous, the pattern reveals considerably more coordination-the group members with either the highest return in ehorhe (Fig. 1b) or the highest endowment in eherho (Fig. 1c) contribute more than the rest of the group. Figure 1d, where endowments and returns are heterogeneous (eherhe), indicates that subjects with the highest endowment still contribute more on average, but the size of relative contributions by these subjects is diminished, particularly when the return from contribution is small for the high-endowment group member.

This visual inspection is confirmed by a conditional analysis of the data. Table 3 reports the results of a panel model that estimates the relative individual contributions as a function of the experimental treatments, the endowment levels, and the rates of return from the public good.7 Five models are estimated-a pooled model provides a between-treatment analysis to estimate treatment effects and general parameter 
effects, and four individual treatment models that provide a within-treatment analysis to estimate treatment-specific parameter effects.

Estimates from the pooled model reveal that relative contributions in the $e^{h o} r^{h e}$ treatment are significantly greater than the omitted baseline $e^{h o} r^{h o}$, while contributions in the $e^{h e} r^{h o}$ and $e^{h e} r^{h e}$ treatments are not. Subsequent analysis will show the relatively larger contributions in ehorhe are due to greater duplicative contributions. The three endowment levels and the three rates of return all have significant negative impacts on individual contributions compared to the omitted baselines of endowment 40 and return 3.75. However, considering the social optimum in the best-shot public good depends on contributions from one member and no contributions from others, the treatment-specific models provide more insight on the interaction of the heterogeneity treatments and the contributions of specific group members.

The estimates confirm the results from the aggregate numbers. First, estimates indicate that the level of endowments has a significant effect on relative contribution levels when endowments are heterogeneous, but not when they are homogeneous. More specifically, estimates reveal that the member with the highest endowment contributes substantially more than the other three members-69 to 80 percentage points more when returns are homogeneous ( $\left(^{\text {he }} r^{h o}\right.$ model) and 42 to 65 points more when returns are heterogeneous ( $e^{\text {he }} r^{\text {he }}$ model).

Second, as with heterogeneous endowments, conditional estimates correspond to the initial findings that heterogeneity in the return of the public good significantly influences group coordination. In particular, estimates reveal that the member with the highest return of 3.75 (omitted) in $e^{h o} r^{h e}$ contributes substantially more than the other three members, though this result is muted when endowments are also heterogeneous $e^{\text {ne }} r^{n e}$ )

Though the panel model estimates clearly show the treatment effects, it is worth pointing out the aggregation masks the extent that group members responded to the focal points. For instance, in the $e^{\text {ho }} r^{\text {he }}$ treatment, group members with the highest or focal point return of 3.75 contributed all (none) of their endowment in $49 \%(27 \%)$ of the cases while those with a lower return contributed all (none) of their endowment $16 \%$ (56\%) of the time. Subjects exhibited even stronger responses when endowments were heterogeneous $\left(e^{n e} r^{n o}\right)$. The group member with the focal-point endowment of 40 contributed all (none) of her endowment $77 \%$ (6\%) of the time while those with smaller endowments contributed all (none) of their endowment in 
Table 3 Individual relative contribution panel models $7 \%$ (82 \%) of the cases. In the next section, we examine how such behavioral responses to focal points affect coordination and efficiency.

\begin{tabular}{|c|c|c|c|c|c|}
\hline & \multirow{2}{*}{$\begin{array}{l}\text { Pooled } \\
\text { model }\end{array}$} & \multicolumn{4}{|c|}{ Treatment-specific models } \\
\hline & & $e^{h o} r^{h o}$ & $e^{h o} r^{h e}$ & $e^{h e} r_{r o}^{h o}$ & $e^{h e} r^{h e}$ \\
\hline Intercept & $\begin{array}{l}0.732^{* * * *} \\
(0.051)\end{array}$ & $\begin{array}{l}0.478^{* * *} \\
(0.072)\end{array}$ & $\begin{array}{l}0.682^{* * *} \\
(0.070)\end{array}$ & $\begin{array}{l}0.947^{* * *} \\
(0.069)\end{array}$ & $\begin{array}{l}0.938^{* * * *} \\
(0.068)\end{array}$ \\
\hline \multicolumn{6}{|l|}{ Treatment } \\
\hline$e^{h o} r^{h e}$ & $\begin{array}{l}0.090^{*} \\
(0.048)\end{array}$ & - & - & - & - \\
\hline$e^{h e} r^{h o}$ & $\begin{array}{l}-0.004 \\
(0.038)\end{array}$ & - & - & - & - \\
\hline$e^{h e} r^{h e}$ & $\begin{array}{l}0.052 \\
(0.044)\end{array}$ & - & - & - & - \\
\hline \multicolumn{6}{|l|}{ Endowment } \\
\hline$e=10$ & $\begin{array}{l}-0.366^{* * *} \\
(0.035)\end{array}$ & $\begin{array}{l}0.015 \\
(0.042)\end{array}$ & $\begin{array}{l}-0.012 \\
(0.041)\end{array}$ & $\begin{array}{l}-0.804^{* * * *} \\
(0.041)\end{array}$ & $\begin{array}{l}-0.647^{* * *} \\
(0.045)\end{array}$ \\
\hline$e=20$ & $\begin{array}{l}-0.342^{* * *} \\
(0.033)\end{array}$ & $\begin{array}{l}0.022 \\
(0.034)\end{array}$ & $\begin{array}{l}-0.042 \\
(0.029)\end{array}$ & $\begin{array}{l}-0.768^{* * *} \\
(0.042)\end{array}$ & $\begin{array}{l}-0.577^{* * *} \\
(0.052)\end{array}$ \\
\hline$e=30$ & $\begin{array}{l}-0.278^{* * *} \\
(0.032)\end{array}$ & $\begin{array}{l}-0.004 \\
(0.041)\end{array}$ & $\begin{array}{l}0.005 \\
(0.031)\end{array}$ & $\begin{array}{l}-0.688^{* * *} \\
(0.046)\end{array}$ & $\begin{array}{l}-0.422^{* * *} \\
(0.057)\end{array}$ \\
\hline \multicolumn{6}{|l|}{ Return } \\
\hline$r=1.25$ & $\begin{array}{l}-0.207^{* * *} \\
(0.027)\end{array}$ & $\begin{array}{l}-0.201^{* * *} \\
(0.049)\end{array}$ & $\begin{array}{l}-0.479^{* * * *} \\
(0.059)\end{array}$ & $\begin{array}{l}-0.039 \\
(0.028)\end{array}$ & $\begin{array}{l}-0.134^{* * *} \\
(0.034)\end{array}$ \\
\hline$r=2.00$ & $\begin{array}{l}-0.139^{* * *} \\
(0.024)\end{array}$ & $\begin{array}{l}-0.118^{* * *} \\
(0.038)\end{array}$ & $\begin{array}{l}-0.369^{* * *} \\
(0.061)\end{array}$ & $\begin{array}{l}0.025 \\
(0.031)\end{array}$ & $\begin{array}{l}-0.132^{* * *} \\
(0.035)\end{array}$ \\
\hline$r=3.00$ & $\begin{array}{l}-0.056^{* * *} \\
(0.021)\end{array}$ & $\begin{array}{l}-0.001 \\
(0.031)\end{array}$ & $\begin{array}{l}-0.229^{* * *} \\
(0.056)\end{array}$ & $\begin{array}{l}0.000 \\
(0.024)\end{array}$ & $\begin{array}{l}-0.035 \\
(0.029)\end{array}$ \\
\hline$N$ & 3840 & 960 & 960 & 960 & 960 \\
\hline$\#$ of clusters & 192 & 48 & 48 & 48 & 48 \\
\hline
\end{tabular}

1. Dependent variable is individual relative contribution (\% of endowment contributed)

2. Estimates condition on individual-specific and period-specific effects

3. Robust standard errors are reported in parentheses unless noted otherwise

4. " $" *$ and ${ }^{* * *}$ indicates significance at the 10,5 and 1 percent levels

\subsection{Efficiency}

With a typical summation public good, the group benefit from contributions exceeds the individual benefit from not contributing, so contributions always improve social welfare. With a best-shot good, duplicative contributions are wasted and decrease social welfare. In fact, it is possible for a group to undercontribute and overcontribute at the same time by the largest contribution being less than the maximum possible and other members making duplicate, wasteful contributions. Further, under- and over 
Table 4 Group play by strategy and treatment

\begin{tabular}{lllll} 
& $e^{h o} r^{h o}$ & $e^{h o} r^{h e}$ & $e^{h e} r^{h o}$ & $e^{h e} r^{h e}$ \\
\hline Pareto-optimal Nash & $10.4 \%$ & $12.1 \%$ & $42.9 \%$ & $20.8 \%$ \\
& $(2.4 \%)$ & $(2.4 \%)$ & $(5.1 \%)$ & $(4.7 \%)$ \\
Overcontribute & $59.6 \%$ & $72.1 \%$ & $42.9 \%$ & $60.4 \%$ \\
\multirow{4}{*}{ Undercontribute } & $(4.0 \%)$ & $(2.9 \%)$ & $(4.9 \%)$ & $(5.7 \%)$ \\
& $50.4 \%$ & $27.9 \%$ & $23.3 \%$ & $42.1 \%$ \\
Over- and undercontribute & $(4.1 \%)$ & $(3.9 \%)$ & $(3.1 \%)$ & $(4.8 \%)$ \\
& $20.4 \%$ & $12.1 \%$ & $9.2 \%$ & $23.3 \%$ \\
& $(3.3 \%)$ & $(3.4 \%)$ & $(2.1 \%)$ & $(5.4 \%)$ \\
\hline
\end{tabular}

The top number in each cell is the percentage of groups that exhibited the corresponding group strategy. Robust standard errors are reported in parentheses

contributions have different welfare consequences. Undercontributing is more costly to the group because it forgoes the potential return to all members while overcontributing only imposes a cost on the individual. Thus, in addition to coordination and efficiency levels, we investigate the underlying nature of the coordination failures across treatments.

We place each group in one of four categories: Pareto-optimal if the group coordinated on the socially optimal Nash strategy, overcontribution if there were duplicate contributions, and undercontribution if the largest endowment was not fully contributed. All groups fall into one of these three categories, but we also include the category over and under to show the extent that a group exhibited both types of coordination failure simultaneously. Table 4 reports the frequency of group play in each category for the four treatments.

Relative to the homogeneous baseline $\left(e^{h o} r^{h o}\right)$, coordination is improved considerably when only endowments are heterogeneous $\left(e^{h e} r^{h o}\right)-42.9 \%$ vs. $10.4 \%(p=0.000)$. This is not the case when only returns are heterogeneous $\left(e^{h o} r^{h e}\right)-12.1 \%$ vs. $10.4 \%(p=$ $0.564)$. Therefore, heterogeneity in endowments facilitates significant increases in coordination, while heterogeneity in returns fails to deliver any real gains. The numbers reveal the source of this result. From Table 4, as well as Fig. 1, we see that the success of endowment heterogeneity occurs because it facilitates a more complete coordination-groups reduce undercontributions by recognizing that a contributor should give her entire endowment, but they also reduce overcontributions by identifying a single contributor. In the case of return heterogeneity, coordination is less completegroups lower undercontributions by recognizing that a contributor should give all, but they fail to identify a single contributor and therefore exhibit greater overcontributions.

We now turn to how these coordination failures affect efficiency. For each treatment, Table 5 reports mean group efficiency as defined as the realized payoffs as 
Table 5 Efficiency: percentage of potential payoffs realized and lost

\begin{tabular}{lllll} 
& $e^{h o} r^{h o}$ & $e^{h o} r^{h e}$ & $e^{h e} r^{h o}$ & $e^{h e} r_{r}^{h e}$ \\
\hline Efficiency & $66.6 \%$ & $80.3 \%$ & $85.3 \%$ & $79.2 \%$ \\
& $(2.2 \%)$ & $(1.6 \%)$ & $(1.8 \%)$ & $(1.8 \%)$ \\
Loss from & $5.0 \%$ & $7.0 \%$ & $1.9 \%$ & $3.2 \%$ \\
overcontributions & $(0.6 \%)$ & $(0.6 \%)$ & $(0.3 \%)$ & $(0.3 \%)$ \\
Loss from & $28.4 \%$ & $12.7 \%$ & $12.8 \%$ & $17.6 \%$ \\
undercontributions & $(2.8 \%)$ & $(2.0 \%)$ & $(1.8 \%)$ & $(1.8 \%)$ \\
\hline
\end{tabular}

Group efficiency is defined as the percentage of gains from the best-shot good captured. Robust standard errors are reported in parentheses

a percentage of possible payoffs. The numbers reveal that efficiency is greatest in $e^{h e} r^{h o}$ at $85.3 \%$, which is significantly greater than the $66.6 \%$ observed in the baseline $(p=0.000)$, and the $80.3 \%$ and $79.2 \%$ observed in $e^{h o} r^{h e}$ and $e^{h e} r^{h e} \quad(p=0.036$ and $p$ $=0.015)$. Efficiency is statistically equivalent across $e^{\text {ho }} r^{\text {he }}$ and $e^{\text {he }} r^{\text {he }} \quad(p=0.642)$, with each being significantly greater than the baseline $(p=0.000)$. Interestingly, though $e^{h o} r^{h e}$ failed to facilitate greater coordination, it did lead to significantly greater efficiency.

Table 5 also provides additional insights to the efficiency results by showing the extent that over- and undercontribution caused groups to not realize potential payoffs.

Following previous results, the numbers show that the relatively high efficiency in $e^{h e} r^{h o}$ occurs from reducing duplicative contributions (overcontributions) and increasing the level of the largest contribution (undercontributions). In the case of heterogeneous returns $\left(e^{h o} r^{h e}\right)$, groups achieved greater efficiency only from increasing the largest contribution. Duplicative contributions actually lowered efficiency relative to the baseline. The numbers reveal that efficiency improves in $e^{\text {ho }} r^{\text {he }}$ despite no significant improvement in coordination because the type of coordination failure changes-shifting from the more costly undercontribution to the less costly overcontribution.

The results provide a compelling story about how heterogeneity affects individual contributions and group coordination in the best-shot public good setting. In the baseline treatment with homogeneous endowments and homogeneous returns, no coordination device stands out, and as expected, coordination on a Nash equilibrium fails sometimes nobody volunteers to contribute his or her endowment while sometimes too many do. When we introduce a focal point through heterogeneous endowments or heterogeneous returns to investment, or both, coordination improves and there are less cases of undercontributing. However, endowment heterogeneity is more effective at fostering coordination since it results in fewer cases of overcontributing as well. Subjects seem to accept more readily that the group member with the highest endowment is the provider of the public good than the subject with the highest marginal return. This can be seen in comparisons between contribution patterns in the two treatments with one source of heterogeneity as well as in the direct comparison in the treatment with both sources. 


\section{Conclusions}

This paper provides the first experimental investigation that combines a best-shot public good contribution game with both heterogeneity in endowments and heterogeneity in marginal returns from the public good. While this combination of asymmetry and heterogeneity is relevant for real-world situations, particularly for international and global public goods, researchers have paid little attention to the potential that such heterogeneity can overcome the coordination problem of a best-shot social dilemma. The study provides four general findings. First, despite the asymmetric nature of the best-shot provision technology, heterogeneity can help overcome coordination problems by providing focal points as a coordination tool. Second, not all focal points are equal. Group members coordinated their contributions more effectively with endowment heterogeneity than return heterogeneity. Third, heterogeneity from multiple sources can complicate coordination. Given endowment heterogeneity, the introduction of heterogeneity in returns reduced coordination and efficiency. Finally, not all coordination failures are the same. While return heterogeneity did not facilitate greater coordination, it did change the nature of failure and improved efficiency.

These findings are important for the understanding of real-world problems, in which the person or country with the highest endowment is not always the one that gains the most from the public good. In the war against international terrorism, the country with the most resources to contribute might also be the country with the most to gain from success. Here the two focal points align, and thus, the country contributes. But in the case of finding a cure for malaria, the focal points do not align. The countries with the most to gain are not the ones with the most resources to contribute to malaria research. Coordination is more difficult and success might require additional mechanisms to facilitate progress. Thus, understanding how asymmetry and heterogeneity can impede and support coordination can improve decision making, including those related to bargaining processes and policy mechanisms.

Acknowledgements We would like to thank Christian Vossler, Jason Shogren, the editor and two anonymous referees for helpful comments, Luke Jones and Shiliang Deng for assistance in the lab, and the College of Businesses at the University of Tennessee and Appalachian State University for generous funding of our work. The first author is also grateful for my time with the Department of Economics at the University of Tennessee during which this research was initiated. 


\section{References}

Bilodeau, M., Childs, J., \& Mestelman, S. (2004). Volunteering a public service: an experimental investigation. Journal of Public Economics, 88, 2839-2855.

Bliss, C., \& Nalebuff, B. (1984). Dragon-slaying and ballroom dancing: the private supply of a public good. Journal of Public Economics, 25, 1-12.

Brandts, J., Cooper, D. J., \& Fatás, E. (2011). Stand by me: help, heterogeneity, and commitment in experimental coordination games. Working paper.

Camerer, C. F. (2003). Behavioral game theory: experiments in strategic interaction. Princeton: Princeton University Press.

Crawford, V. P., Gneezy, U., \& Rottenstreich, Y. (2008). The power of focal points is limited: even minute payoff asymmetry yield large coordination failures. The American Economic Review, 98, 1443-1458.

Deck, C., \& Nikiforakis, N. (2012). Perfect and omperfect real-times monitoring in a minimum-effort game. Experimental Economics, 15(1), 71-88.

Diekmann, A. (1985). Volunteer's dilemma. The Journal of Conflict Resolution, 29, 605610.

Engelmann, D., \& Grimm, V. (2012). Mechanisms for Efficient Voting with Private Information about Preferences. Economic Journal, 122(563), 1010-1041.

Fischbacher, U. (2007). Z-Tree: Zurich toolbox for ready-made economic experiments. Experimental Economics, 10, 171-178.

Goeree, J. K., Holt, C., \& Smith, A. M. (2005). An experimental examination of the volunteer's dilemma. Unpublished working paper.

Harrison, G. W., \& Hirshleifer, J. (1989). An experimental evaluation of weakest link/best shot models of public goods. Journal of Political Economy, 97(1), 201-225.

Healy, A. J., \& Pate, J. G. (2012). Cost asymmetry and uncertainty in an experimental volunteer's dilemma. Working paper.

Hirshleifer, J. (1983). From weakest-link to best-shot: the voluntary provision of public goods. Public Choice, 41, 371-386.

Hörisch, H., \& Kirchkamp, O. (2010). Less fighting than expected-experiments with wars of attrition and all-pay auctions. Public Choice, 144, 347-367. 
Holzinger, K. (2001). Aggregation technology of common goods and its strategic consequences: global warming, biodiversity, and siting conflicts. European Journal of Political Research, 40, 117-138. Kaplan, T. R., \& Ruffle, B. J. (2012). Which way to cooperate. Economic Journal, 122(563), 1042-1068.

Kroll, S., Cherry, T. L., \& Shogren, J. F. (2007). The impact of endowment heterogeneity and origin on contributions in best-shot public good games. Experimental Economics, $10,411-428$.

Mehta, J., Starmer, C., \& Sugden, R. (1994). The nature of salience: an experimental investigation of pure coordination games. The American Economic Review, 84(3), 658673.

Rubinstein, A., Tversky, A., \& Heller, D. (1996). Naïve strategies competitive games. In W. Albers, W. Guth, P. Hammerstein, B. Moldovanu, \& E. van Damme (Eds.), Understanding strategic interaction-essays honor of Reinhard Selton (pp. 394-402). Berlin: Springer.

Sandler, T. (2006). Regional public goods and international organizations. Review of International Organizations, 1, 5-25.

Schelling, T. (1960). The strategy of conflict. Cambridge: Harvard University Press.

Sheremeta, R. M. (2011). Perfect-substitutes, best-shot and weakest-link contests between groups. The Korean Economic Review, 27, 5-32.

Straub, P. (1995). Risk dominance and coordination failures in static games. The Quarterly Review of Economics and Finance, 35(4), 339-363.

Van Huyck, J. B., Battalio, R. C., \& Beil, R. O. (1990). Tacit coordination games, strategic uncertainty, and coordination failure. The American Economic Review, 80(1), 234-248. 